The University of San Francisco

USF Scholarship: a digital repository @ Gleeson Library | Geschke Center

Winter 12-16-2016

\title{
Vitamin D, Calcium and Blood Pressure in the U.S.
}

Sarah Bean

University of San Francisco, sibean@dons.usfca.edu

Follow this and additional works at: https://repository.usfca.edu/capstone

Part of the Clinical Epidemiology Commons

\section{Recommended Citation}

Bean, Sarah, "Vitamin D, Calcium and Blood Pressure in the U.S." (2016). Master's Projects and Capstones. 427.

https://repository.usfca.edu/capstone/427

This Project/Capstone is brought to you for free and open access by the Theses, Dissertations, Capstones and Projects at USF Scholarship: a digital repository@ Gleeson Library | Geschke Center. It has been accepted for inclusion in Master's Projects and Capstones by an authorized administrator of USF Scholarship: a digital repository @ Gleeson Library | Geschke Center. For more information, please contact repository@usfca.edu. 
Running Head: VITAMIN D, CALCIUM AND BLOOD PRESSURE IN U.S.

Vitamin D, Calcium and Blood Pressure in the U.S.

Sarah Bean

MPH Candidate 2016

University of San Francisco 


\begin{abstract}
According to the Centers for Disease Control and Prevention (CDC), 75 million Americans have high blood pressure, which is roughly one in every three adults ${ }^{[1]}$. High blood pressure can lead to a host of health problems including an increased risk of cardiovascular disease which is the leading cause of the death in the U.S. ${ }^{[1]}$. Over the past decade, vitamin D and calcium have received increased attention for their potential roles in improving cardiovascular health. The active form of vitamin $\mathrm{D}, 1,25$-hydroxyvitamin $\mathrm{D}(25[\mathrm{OH}] \mathrm{D})$, may influence blood pressure by increasing gastrointestinal calcium absorption. The objectives of this study were to first examine the association between blood pressure and blood serum $25(\mathrm{OH}) \mathrm{D}$ levels, and then explore the interaction between $25(\mathrm{OH}) \mathrm{D}$, calcium intake, and blood pressure. Cross-sectional analysis featured 24,844 non-institutionalized, relatively healthy U.S. adults aged 20-80 years from three cycles of the National Health and Examination Survey (NHANES) during 2001 to 2006. Linear regression models were used to determine the adjusted association of $25(\mathrm{OH}) \mathrm{D}$ categories with blood pressure. An interaction term between $25(\mathrm{OH}) \mathrm{D}$ and calcium intake was fitted in the fully adjusted regression model. All analyses accounted for the complex survey design. The mean age was $37.5(0.3)$ and $48.6 \%$ of participants were male. Mean systolic blood pressure (SBP) and diastolic blood pressure (DBP) in mmHg were $120.3(0.3)$ and 69.3 (0.2), respectively. Linear regression models showed that SBP, but not DBP, was negatively and significantly associated with increasing $25(\mathrm{OH}) \mathrm{D}$ levels. Moreover, a significant interaction between $25(\mathrm{OH}) \mathrm{D}$ and calcium intake levels was noted for $\mathrm{DBP}(\mathrm{P}=0.040)$. Conclusively, the association between 25(OH)D levels and DBP may differ by calcium intake in the U.S. population.
\end{abstract}


VITAMIN D, CALCIUM AND BLOOD PRESSURE IN U.S.

\section{Introduction}

In 2016, according to the Centers for Disease Control and Prevention (CDC), 75 million Americans have high blood pressure, which is roughly one in three adults ${ }^{[1]}$. The CDC also reports that one in every three U.S. adults is prehypertensive (i.e. at risk for high blood pressure) ${ }^{[1]}$. High blood pressure, or hypertension, is defined as having a resting systolic blood pressure (SBP) of $\geq 140 \mathrm{mmHg}$ and a resting diastolic blood pressure (DBP) of $\geq 80 \mathrm{mmHg}^{[1]}$. Hypertension can lead to a host of health problems including cardiovascular diseases (CVD), such as coronary artery disease and stroke, which are the leading causes of death in the U.S. to date $^{[1]}$. For instance, in 2014, high blood pressure was a primary or contributing cause of death for roughly 410,000 Americans, exceeding 1,100 deaths per day ${ }^{[1]}$. Moreover, mortality rates from hypertension and CVD exemplify the ongoing the racial and socioeconomic disparities which gravely affect nationwide health outcomes. The American Heart Association (AHA) reports that CVD mortality rates are 33\% higher for Blacks compared to the overall U.S. population, and that Blacks are nearly twice as likely to have a first stroke and much more likely to die from a stroke than whites ${ }^{[2]}$. Interestingly, epidemiological studies examining blood pressure among racial/ethnic minorities have found that those most at risk for developing hypertension were also deficient in vitamin $\mathrm{D}^{[3-6]}$. Similarly, prospective studies have also shown an inverse relationship between calcium deficiency and high blood pressure ${ }^{[7]}$. Given that vitamin D and calcium deficiency are relatively easy to treat with sun exposure and diet modifications, supplementation may be a simple and cost-effective over-the-counter option for populations at an increased risk for hypertension as well as those with limited access to preventative CVD health care services. 
VITAMIN D, CALCIUM AND BLOOD PRESSURE IN U.S.

\section{Background}

Vitamin D and calcium have received increased attention for their potential roles in improving cardiovascular health, more specifically their ability to reduce blood pressure. Diets high in calcium, such as the Dietary Approaches to Stop Hypertension (DASH) diet and low-fat dairy diets, have been associated with lower blood pressure ${ }^{[9-10]}$. Likewise, a meta-analysis study concluded that calcium supplements of at least 1,000 mg significantly lowered both systolic and diastolic blood pressure ${ }^{[11]}$. Due to its role in regulating calcium via the renin-angiotensin system in the kidneys, researchers have also investigated the relationship between vitamin $\mathrm{D}$ and blood pressure ${ }^{[12-14]}$. 1,25-hydroxyvitamin $\mathrm{D}(25[\mathrm{OH}] \mathrm{D})$, the active form of vitamin $\mathrm{D}$, is primarily responsible for regulating calcium absorption in the gastrointestinal tract ${ }^{[14]}$. Vitamin D deficiency can impair calcium homeostasis by decreasing the absorption of calcium ${ }^{[14]}$. To explore the potential relationship between vitamin $\mathrm{D}$ and blood pressure, epidemiologists and clinical researchers have utilized data from the National Health and Nutrition Examination Survey (NHANES). A comparative chart summarizing the following NHANES studies is provided in Appendix C.

In 2007, Scragg et al. used NHANES III data to examine the association between blood serum $25(\mathrm{OH}) \mathrm{D}$ and blood pressure in 12,644 U.S. adults 20 years of age or older. Results showed a significant inverse relationship between SBP, pulse pressure, and 25(OH)D while controlling for gender, ethnicity, and physical activity. More specifically, SBP was found to be $3.0 \mathrm{mmHg}$ lower $(\mathrm{P}<0.001)$ in the highest $25(\mathrm{OH}) \mathrm{D}$ category $(\geq 85 \mathrm{nmol} / \mathrm{L})$; DBP was found to be $1.6(0.6) \mathrm{mmHg}$ lower $(\mathrm{P}<0.05)$ at $\geq 85 \mathrm{nmol} / \mathrm{L}^{[6]}$. A similar 2007 study analyzed the effects of 25(OH)D on CVD risk factors in 15,088 U.S. adults aged 20 years or older using 
VITAMIN D, CALCIUM AND BLOOD PRESSURE IN U.S.

NHANES III data. Martens, et. al found an association between vitamin D and CVD risk factors while controlling for a wide range of covariates including socio-demographics, blood glucose level, total cholesterol, and serum albumin level. Statistical analysis revealed 25(OH)D levels were significantly lower in the following demographics: women, participants above the age of 60 , years, racial/ethnic minorities, and participants with obesity, hypertension, and diabetes $(\mathrm{P}<0.001)^{[12]}$. In contrast, Judd, et al. investigated whether $25(\mathrm{OH}) \mathrm{D}$ levels affected SBP in 7,699 non-hypertensive U.S. adults with data from NHANES III. Findings indicated that higher SBP was associated with lower 25(OH)D levels in non-Hispanic whites, but not in non-Hispanic blacks ${ }^{[15] .}$ However, when controlling for age, gender and body mass index (BMI), this association was no longer significant. Judd et al. did not include races outside of non-Hispanic whites and non-Hispanic blacks. In a recent 2016 study, Vogt, et al., utilized data from NHANES 2001-2006 to examine whether waist circumference influenced the effects of 25(OH)D on blood pressure in 10, 331 U.S. men and non-pregnant women aged 20 years or older. Linear regression analysis demonstrated that abdominally obese participants with low 25(OH)D levels $(<15 \mathrm{ng} / \mathrm{ml})$ had a $3.7 \mathrm{mmHg}$ higher mean SBP $(\mathrm{P}<0.001)$ and a $2.1 \mathrm{mmHg}$ higher mean DBP $(\mathrm{P}<0.05)$, compared to mean SBP and DBP in both abdominally overweight and normal waist participants with adjustment for all covariates ${ }^{[16]}$.

Overall, findings from NHANES data appear promising in their attempts to establish a clear connection between vitamin D and blood pressure. However, as noted in the above studies, the cross-sectional survey design was a major limitation as cause and effect cannot be differentiated. Furthermore, calcium intake was not included as an adjusted variable. Thus, no interactions between vitamin $\mathrm{D}$, calcium intake, and blood pressure were observed. Given the 
VITAMIN D, CALCIUM AND BLOOD PRESSURE IN U.S.

relationship between vitamin $\mathrm{D}$ and calcium homeostasis in the body, it is critical to examine the interaction between $25(\mathrm{OH}) \mathrm{D}$, calcium, and blood pressure.

\section{Scope of the Project}

$\underline{\text { Goal \& Objectives }}$

Goal

The goal of this study was to determine whether vitamin D and calcium play a role in improving cardiovascular health by reducing blood pressure.

\section{Objectives}

The objectives of the study were to first examine the association between blood pressure and varying blood serum $25(\mathrm{OH}) \mathrm{D}$ levels, and then explore the interaction between varying blood serum $25(\mathrm{OH}) \mathrm{D}$ levels, calcium intake, and blood pressure.

$\underline{\text { Methods }}$

Study Population

The study population featured a pooled sample of 24,844 non-institutionalized, relatively healthy adults from three cycles of the NHANES during 2001 to 2006 . NHANES is a national program conducted by the National Center for Health Statistics (NCHS), which is a major sector of the CDC ${ }^{[17]}$. NHANES aims to assess the health and nutrition status of the U.S. population through ongoing surveys that consist of both at-home administered questionnaires and physical examinations at nationwide Mobile Examination Centers (MECs) ${ }^{[17]}$. Data from NHANES are used in numerous clinical and epidemiological studies, and often serve as a the backbone for public health policies and community health programs and services ${ }^{[17]}$. 
VITAMIN D, CALCIUM AND BLOOD PRESSURE IN U.S.

In the current study, participants were included if they were 20 years of age or older with a glomerular filtration rate (GFR) of $60 \mathrm{~mL} / \mathrm{min} / 1.73 \mathrm{~m}^{2}$ or above. Participants were excluded from the study if they were younger than 20 years of age or had a GFR that was less than $60 \mathrm{~mL} / \mathrm{min} / 1.72 \mathrm{~m}^{2}$. A GFR less than 60 would indicate kidney disease and subsequently higher blood pressure ${ }^{[18]}$. Participants were also excluded if they had missing values for any of the following questions and/or measurements: age, calcium intake, caloric intake, systolic blood pressure, blood serum 25(OH)D. NHANES data were approved by the Institutional Review Board (IRB) and written consent was obtained from all NHANES participants ${ }^{[19]}$.

\section{Blood Pressure}

Blood pressure was taken at the MECs, where participants were seated and rested for at least five minutes. Using an appropriately sized cuff, resting blood pressure was measured using a mercury sphygmomanometer by a trained study physician. Systolic blood pressure and diastolic blood pressure were reported from the average of three measurements taken approximately one minute apart ${ }^{[16]}$.

\section{Calcium Intake}

Calcium intake was measured through 24-hour dietary recall interviews that were conducted in person by trained interviewers in the MECs. A second 24-hour dietary recall was collected via telephone three to 10 days after the MEC exam ${ }^{[19]}$.

\section{Vitamin D}

Blood was collected from all participants during the physical examination at MECs by certified phlebotomists. Participants with hemophilia or those who received chemotherapy within the past four weeks were excluded from the blood draw ${ }^{[16]}$. Blood serum $25(\mathrm{OH}) \mathrm{D}$ was 
VITAMIN D, CALCIUM AND BLOOD PRESSURE IN U.S.

measured at the National Center for Environmental Health using a radioimmunoassay kit. Serum 25(OH)D was then calibrated to $25(\mathrm{OH}) \mathrm{D}$ measured with LC-MS with an NIST standard. In the current study, 25(OH)D levels were categorized into four groups: $<30 \mathrm{nmol} / \mathrm{L}$; $30-<50 \mathrm{nmol} / \mathrm{L} ; 50-<75 \mathrm{nmol} / \mathrm{L}$; and $>75 \mathrm{nmol} / \mathrm{L}$. Cut points per 25(OH)D level were based on guidelines from the Institute of Medicine.

\section{Covariates}

Information regarding age, sex, ethnicity, level of education, alcohol consumption, presence of diabetes (as told by a physician) and current use of prescribed blood pressure medication(s) were obtained from the at-home questionnaire ${ }^{[16]}$. BMI was taken at the MECs and calculated as weight in kilograms divided by height in meters squared ${ }^{[16]}$. GFR was also measured at the MECs with a single spot urine test to gauge serum creatinine and urine albumin ${ }^{[16]}$. Statistical Analysis

Statistical analysis was performed in STATA 12. All analyses included the cluster statement, strata statement, and sample weights. Means and standard deviations were used to summarize the characteristics of the study population (Appendix D.1). Continuous and categorical variables were compared across varying 25(OH)D levels (Appendix D.2). Linear regression models were fitted to look at the changes in the parameter estimates with adjustment for all confounders (Appendix D.3). Model I adjusted for age, gender, race, and education level. Model II adjusted for covariates in Model I as well as GFR, caloric intake, calcium intake, and use of blood pressure medications. Calcium intake was also log transformed in Model II to account for its non-normal distribution. Model III included adjustment for all 
VITAMIN D, CALCIUM AND BLOOD PRESSURE IN U.S.

covariates in Model II as well as diabetes and alcohol use. Scatter plot diagrams were constructed to graphically describe the association between $25(\mathrm{OH}) \mathrm{D}$ levels and SBP and DBP (Appendix D.4). Box plots were used to compare demographics (e.g. sex, race, education level) by $25(\mathrm{OH}) \mathrm{D}$ categories (Appendix D.5). Spline plots with five knots were constructed to graph SBP and DBP by 25(OH)D with adjustment for age, gender, race, BMI, GFR, calcium intake, and use of blood pressure medications (Appendix D.6). Lastly, interaction terms between $25(\mathrm{OH}) \mathrm{D}$ and $\log$ of calcium (i.e. calcium intake) were fitted in the regression model with adjustment for all covariates. Contour plots were created to explore interactions between 25(OH)D, log of calcium, and blood pressure (Appendix D.7).

\section{Public/Population Health Impact: Results, Limitations and Significance $\underline{\text { Results }}$}

Table I provides detailed characteristics among males and females in the study (Appendix D.1). In the study population, the mean age was $37.5(0.3)$ years and $48.6 \%$ of the participants were male. The pooled sample consisted of $69.9 \%$ non-Hispanic white, $11.1 \%$ Black, $8.8 \%$ Mexican, and 10.1\% Other. The mean SBP and DBP in mmHg were $120.3(0.3)$ and $69.3(0.2)$, respectively. Mean BMI was 26.7 with $69.6 \%$ of participants having a BMI of less than 30. In regards to vitamin D levels, $5 \%$ of participants measured at $<30 \mathrm{nmol} / \mathrm{L}, 20.8 \%$ measured at $30-<50 \mathrm{nmol} / \mathrm{L}, 39.8 \%$ measured at $50-<75 \mathrm{nmol} / \mathrm{L}$, and $34.3 \%$ measured at $>75 \mathrm{nmol} / \mathrm{L}$.

Table II compares the mean differences of both continuous and categorical variables across serum 25(OH)D levels (Appendix D.2). Systolic blood pressure was highest at the lowest 25(OH)D level (<30 nmol/L) at $123.9(0.7) \mathrm{mmHg}$; diastolic blood pressure was also highest in the lowest 25(OH)D level at $70.7(0.5) \mathrm{mmHg}$. However, as 25(OH)D levels increased, both SBP 
VITAMIN D, CALCIUM AND BLOOD PRESSURE IN U.S.

and DBP decreased. In the highest $25(\mathrm{OH}) \mathrm{D}$ category $(>75 \mathrm{nmol} / \mathrm{L})$, both SBP and DBP were lowest at $118.2(0.2) \mathrm{mmHg}$ and $68.1(0.3) \mathrm{mmHg}$, respectively. Similarly, this inverse trend was observed for BMI, as BMI was $30.9(0.4)$ at $<30 \mathrm{nmol} / \mathrm{L}$, and lowest at $24.3(0.2)$ at $>75 \mathrm{nmol} / \mathrm{L}$. Calcium intake was lowest when 25(OH)D was lowest at $649.2(13.8) \mathrm{mg}$, and highest when 25(OH)D was highest at $984.4(12.9) \mathrm{mg}$. Among race categories, Blacks had the highest percentage $(49 \%)$ of $25(\mathrm{OH}) \mathrm{D}$ that was less than $30 \mathrm{nmol} / \mathrm{L}$ compared to other racial groups. Non-Hispanic whites had the highest percentages in the highest serum 25(OH)D levels, with $75.4 \%$ at $50->75 \mathrm{nmol} / \mathrm{L}$ and $80.2 \%$ at $>75 \mathrm{nmol} / \mathrm{L}$. This is finding was further demonstrated using a box plot diagram, which compared the mean differences in $25(\mathrm{OH}) \mathrm{D}$ levels by race categories (Appendix D.4).

Table III shows the results of the three linear regression models in all study participants (Appendix D3). In all three models, SBP, but not DBP, was negatively and significantly associated with an increase in 25(OH)D level $(\mathrm{P}<0.05)$. Most notably in Model III, while controlling for all covariates, SBP was $-1.54 \mathrm{mmHg}$ lower $(95 \% \mathrm{CI}-3.08,-0.01)$ at the $25(\mathrm{OH}) \mathrm{D}$ $50-<75 \mathrm{nmol} / \mathrm{L}$ level compared to the lowest $25(\mathrm{OH}) \mathrm{D}$ level $(<30 \mathrm{nmol} / \mathrm{L})$. This was the only statistically significant difference when adjusting for all covariates $(\mathrm{P}<0.048)$. In addition, $\mathrm{P}$ trend analysis for all three models was statistically significant for both SBP and DBP. This finding suggests a linear trend between increasing $25(\mathrm{OH}) \mathrm{D}$ levels and decreasing blood pressure values. Lastly, a significant interaction between 25(OH)D and calcium intake levels was noted for $\mathrm{DBP}(\mathrm{P}=0.040)$, but not for $\mathrm{SBP}(\mathrm{P}=0.675)$. A contour plot was used to observe this interaction (Appendix D.7). In reference to the contour plot, as log of calcium increased without any increase in $25(\mathrm{OH}) \mathrm{D}$, predicted DBP was highest at $70.1 \mathrm{mmHg}$. However, as $25(\mathrm{OH}) \mathrm{D}$ 
VITAMIN D, CALCIUM AND BLOOD PRESSURE IN U.S.

levels increased along with log of calcium, DBP lowered. DBP was lowest at $67.9 \mathrm{mmHg}$ when $\log$ of calcium and $25(\mathrm{OH}) \mathrm{D}$ were at their highest.

\section{$\underline{\text { Limitations }}$}

It should be noted that there were several limitations to the study. Due to the cross-sectional study design, causation among vitamin D, calcium, and blood pressure could not be determined. Although calcium intake through dietary foods was included, additional calcium supplementation was not accounted for in the study. Furthermore, there was error in the measurement of calcium as it was difficult to measure dietary intake, especially when relying on 24-hour dietary recall. Physical activity and seasons were also not included in the adjusted covariates, which may have resulted in residual confounding.

\section{$\underline{\text { Significance }}$}

In this cross-sectional study of relatively healthy, non-institutionalized U.S. adults, a significant inverse relationship was found among increasing vitamin D levels and SBP, even after accounting for calcium intake $(\mathrm{P}<0.05)$. In contrast, there was no significant interaction between vitamin D, calcium, and SBP. However, there was a significant interaction between vitamin $\mathrm{D}$, calcium, and DBP $(\mathrm{P}<0.05)$. The findings of this study are consistent with the growing body of research suggesting that vitamin D and calcium are inversely associated with blood pressure.

Based on the limitations of this study as well as previous studies, it is evident that more comprehensive research is needed as a definitive link between vitamin D, calcium intake, and hypertension has not yet been established. Complex prospective, clinical, and longitudinal studies will require greater funding, which currently appears to be lacking. According to the 
VITAMIN D, CALCIUM AND BLOOD PRESSURE IN U.S.

National Institute of Health, in the 2017 fiscal year, hypertension is estimated to receive \$222 million in supportive funding while HIV/AIDS is estimated to receive $\$ 3$ billion ${ }^{[20]}$. Given the sociopolitical awareness surrounding HIV/AIDS, the difference does not seem too off-putting. However, when looking at the U.S. mortality rates for hypertension and HIV/AIDS, it is hard not to wonder why funding is limited for such a prevalent condition; in 2014, hypertension had the second highest mortality rate of 410,624 compared to HIV/AIDS mortality of $8,619^{[20]}$. To increase research funding for hypertension, grant proposals are needed. Research grants would help to further examine the relationship between vitamin D, calcium, and blood pressure as well as other potential dietary sources and/or supplements that could decrease the risk of high blood pressure, especially among racial/ethnic minorities. Additionally, due to the disproportionate percentage of Blacks with vitamin D deficiency, hypertension, and CVD, future research should examine hypertension morbidity and mortality as it relates to racial/ethnic disparities and social determinates.

From a public health perspective with respect to the ecological model, much can be done at each level to advance the knowledge and practices of hypertension research, awareness, and prevention. With increased funding to hypertension, policies can be tailored to improve vitamin $\mathrm{D}$ and calcium deficiency as well as the frequency and accessibility of blood pressure screenings in communities prone to the highest CVD risk factors. Increased funding and refined research findings would also strengthen community partnerships through culturally appropriate, preventative CVD resources, educational programs, and awareness campaigns. Social media platforms can be utilized to engage communities about the social determinants of nutrient deficiencies, hypertension and CVD, improve health literacy, and disseminate recent findings in 
VITAMIN D, CALCIUM AND BLOOD PRESSURE IN U.S.

hypertension research to marginalized populations. Greater awareness of hypertension can influence health care systems, local health departments, and clinics to implement more screenings to detect nutrient deficiencies in prehypertensive and hypertensive adults. At the intrapersonal level, primary care physicians can recommend dietary supplements and foods high in calcium and vitamin D to patients; friends and family members can encourage one another to eat foods that are high in vitamin D and calcium, get regular blood pressure screenings as well as screenings for any nutrient deficiencies. Finally, at the intrapersonal level, increased health literacy, knowledge of preventative resources like dietary supplements along with improved access to health screenings can empower individuals to take proactive steps towards reducing their risk of nutrient deficiencies, hypertension, and CVD.

\section{Conclusion}

High blood pressure is a precursor to cardiovascular diseases, such as coronary heart disease and stroke, which are the leading causes of death in the United States ${ }^{[1]}$. Epidemiologists and clinical researchers are exploring simple and cost-effective dietary approaches to combat cardiovascular diseases, especially in vulnerable and marginalized communities. More recently, vitamin D and calcium have received increased attention for their potentials roles in lowering systolic and diastolic blood pressure. In the current cross-sectional study, a significant inverse relationship was found among increasing vitamin D levels and SBP, even after accounting for calcium intake. There was also a significant interaction between vitamin D, calcium, and DBP. Due to limitations in the survey design, more complex prospective studies and clinical research are needed to establish a definitive link between vitamin D, calcium intake, and blood pressure. 


\section{References}

1.) Centers for Disease Control and Prevention. (2016). High Blood Pressure Fact Sheet. Retrieved from: http://www.cdc.gov/dhdsp/data_statistics/fact_sheets/fs_bloodpressure.htm

2.) American Heart Association. (n.d.). Fact Sheet: CVD Health Disparities. Retrieved from: https:/www.heart.org/idc/groups/heart-public/@wcm/@hcm/@ml/documents/downloadable/uc m_429240.pdf

3.) Forman, J. P., Scott, J. B., Ng, K., Drake, B. F., Suarez, E. G., Hayden, D. L., ... \& Giovannucci, E. L. (2013). Effect of vitamin D supplementation on blood pressure in blacks. Hypertension, 61(4), 779-785.

4.) Forman, J. P., Bischoff-Ferrari, H. A., Willett, W. C., Stampfer, M. J., \& Curhan, G. C. (2005). Vitamin D intake and risk of incident hypertension results from three large prospective cohort studies. Hypertension, 46(4), 676-682.

5.) Forman, J. P., Curhan, G. C., \& Taylor, E. N. (2008). Plasma 25-hydroxyvitamin D levels and risk of incident hypertension among young women. Hypertension, 52(5), 828-832.

6.) Scragg, R., Sowers, M., \& Bell, C. (2007). Serum 25-hydroxyvitamin D, ethnicity, and blood pressure in the Third National Health and Nutrition Examination Survey. American journal of hypertension, 20(7), 713-719

7.) Yuasa, S., Sumikura, T., Yura, T., Takahashi, N., Shoji, T., Uchida, K., ... \& Takamitsu, Y. (1996). Effect of low dietary calcium intake on blood pressure and pressure natriuresis response in rats: a possible role of the renin-angiotensin system. Blood pressure, 5(2), 121-127.

8.) Moore, T. J., Conlin, P. R., Ard, J., Svetkey, L. P., \& DASH Collaborative Research Group. (2001). DASH (Dietary Approaches to Stop Hypertension) diet is effective treatment for stage 1 isolated systolic hypertension. Hypertension, 38(2), 155-158.

9.) Wang, L., Manson, J. E., Buring, J. E., Lee, I. M., \& Sesso, H. D. (2008). Dietary intake of dairy products, calcium, and vitamin $\mathrm{D}$ and the risk of hypertension in middle-aged and older women. Hypertension, 51(4), 1073-1079.

10.) Van Mierlo, L. A. J., Arends, L. R., Streppel, M. T., Zeegers, M. P. A., Kok, F. J., Grobbee, D. E., \& Geleijnse, J. M. (2006). Blood pressure response to calcium supplementation: a meta-analysis of randomized controlled trials. Journal of human hypertension, 20(8), 571-580. 
11.) Fanari, Z., Hammami, S., Hammami, M. B., Hammami, S., \& Abdellatif, A. (2015). Vitamin D deficiency plays an important role in cardiac disease and affects patient outcome: Still a myth or a fact that needs exploration?. Journal of the Saudi Heart Association, 27(4), 264-271.

12.) Martins, D., Wolf, M., Pan, D., Zadshir, A., Tareen, N., Thadhani, R., \& Norris, K. (2007). Prevalence of cardiovascular risk factors and the serum levels of 25-hydroxyvitamin D in the United States: data from the Third National Health and Nutrition Examination Survey. Archives of internal medicine, 167(11), 1159-1165.

13.) Cohen, D. L., \& Townsend, R. R. (2012). Should we be recommending vitamin D supplementation for hypertension and cardiovascular disease prevention?. The Journal of Clinical Hypertension, 14(11), 816-818.

14.) Ullah, M. I., Uwaifo, G. I., Nicholas, W. C., \& Koch, C. A. (2009). Does vitamin D deficiency cause hypertension? Current evidence from clinical studies and potential mechanisms. International journal of endocrinology, 2010

15.) Judd, S. E., Nanes, M. S., Ziegler, T. R., Wilson, P. W., \& Tangpricha, V. (2008). Optimal vitamin D status attenuates the age-associated increase in systolic blood pressure in white Americans: results from the third National Health and Nutrition Examination Survey. The American Journal of Clinical Nutrition, 87(1), 136-141.

16.) Vogt, S., Baumert, J., Peters, A., Thorand, B., \& Scragg, R. (2016). Waist circumference modifies the association between serum $25(\mathrm{OH}) \mathrm{D}$ and systolic blood pressure: results from NHANES 2001-2006. Journal of hypertension, 34(4), 637-645.

17.) National Center for Health Statistics. (2014). NHANES Overview. Retrieved from: https:/www.cdc.gov/nchs/data/nhanes/nhanes_13_14/2013-14_overview_brochure.pdf

18) National Institute of Diabetes and Digestive and Kidney Diseases. (2014). High Blood Pressure and Kidney Disease. Retrieved from:

https://www.niddk.nih.gov/health-information/health-topics/kidney-disease/high-blood-pressureand-kidney-disease/Pages/facts.aspx

19.) Centers for Disease Control and Prevention. (2015). 2005-2006 National Health and Nutrition Examination Survey. Retrieved from:

https:/www.cdc.gov/nchs/nhanes/nhanes2005-2006/questionnaires05_06.htm 
VITAMIN D, CALCIUM AND BLOOD PRESSURE IN U.S.

20.) National Institutes of Health. (2016). Estimates of Funding for Various Research, Condition, and Disease Categories. Retrieved from:

https://report.nih.gov/categorical_spending.aspx\#legend8

21.) Kramer, H., Han, C., Post, W., Goff, D., Diez-Roux, A., Cooper, R., ... \& Shea, S. (2004). Racial/ethnic differences in hypertension and hypertension treatment and control in the multi-ethnic study of atherosclerosis (MESA).American journal of hypertension, 17(10), 963-970. 


\section{Appendix C: NHANES Literature Review Table}

\section{Recent NHANES Research Examining Hypertension and 25(OH)D}

\begin{tabular}{|c|c|c|c|c|c|}
\hline $\begin{array}{l}\text { Author, } \\
\text { Year }\end{array}$ & Objective(s) & (n) & $25(O H) D$ & Adjusted & Findings \\
\hline $\begin{array}{l}\text { Scragg, } \\
\text { R., et al., } \\
2007\end{array}$ & $\begin{array}{l}\text { Determine whether } \\
\text { vitamin D is inversely } \\
\text { related to SBP and DBP. } \\
\text { Determine whether } \\
\text { ethnic differences in } \\
\text { 25(OH)D levels explain } \\
\text { BP differences. }\end{array}$ & 12,644 & DiaSorin & $\begin{array}{l}\text { Sex, ethnicity, leisure } \\
\text { time physical activity }\end{array}$ & $\begin{array}{l}\text { Inverse relationship between } \\
\text { SBP and pulse pressure and } \\
\text { vitamin D. }\end{array}$ \\
\hline $\begin{array}{l}\text { Judd, S., } \\
\text { et al., } \\
2007\end{array}$ & $\begin{array}{l}\text { Determine whether } \\
25(\mathrm{OH}) \mathrm{D} \text { levels are } \\
\text { related to SBP. }\end{array}$ & 7,699 & DiaSorin & Age, sex, BMI & $\begin{array}{c}\text { Lower } 25(\mathrm{OH}) \mathrm{D} \text { levels are } \\
\text { associated with higher blood } \\
\text { pressure. } \\
\text { *Not significant when } \\
\text { controlling for age. } \\
\text { * Not significant in Black } \\
\text { population }\end{array}$ \\
\hline $\begin{array}{l}\text { Martins, } \\
\text { D., et al., } \\
2007\end{array}$ & $\begin{array}{l}\text { Examine the association } \\
\text { between vitamin } \mathrm{D} \text { and } \\
\text { select CVD risk factors in } \\
\text { US adults. }\end{array}$ & 15,088 & INCSTAR & $\begin{array}{l}\text { Age, race/ethnicity, sex, } \\
\text { BP level, history of } \\
\text { hyper., blood glucose } \\
\text { level, history of diabetes, } \\
\text { BMI, triglyceride level, } \\
\text { total cholesterol, } \\
\text { non-high- density } \\
\text { lipoprotein cholesterol,, } \\
\text { serum albumin level, } \\
\text { eGFR, albuminuria }\end{array}$ & $\begin{array}{c}\text { Vitamin D levels are associated } \\
\text { with CVD risk factors in U.S. } \\
\text { adults. }\end{array}$ \\
\hline $\begin{array}{l}\text { Vogt, S., } \\
\text { et al., } \\
2016\end{array}$ & $\begin{array}{l}\text { Examine whether waist } \\
\text { circumference modifies } \\
\text { the relationship among } \\
\text { vitamin D and BP in } \\
\text { NHANES (2001-2006). }\end{array}$ & 10,331 & DiaSorin & $\begin{array}{l}\text { Age, sex, waist circum., } \\
\text { ethnicity, season, } \\
\text { physical activity, alcohol } \\
\text { use, smoking, education, } \\
\text { diabetes, kidney disease, } \\
\text { HBP meds. }\end{array}$ & $\begin{array}{l}\text { Waist circumference } \\
\text { significantly modifies vitamin } \\
\mathrm{D} \text { and SBP, which is stronger } \\
\text { in abdominally obese than in } \\
\text { abdominally overweight and } \\
\text { normal waist participants. }\end{array}$ \\
\hline
\end{tabular}




\section{Appendix D.1: Table I: Study Population Characteristics}

Table I: Study Population Characteristics in NHANES (2001-2006)

\begin{tabular}{|c|c|c|c|}
\hline & $\begin{array}{c}\text { Male } \\
n=12,070\end{array}$ & $\begin{array}{c}\text { Female } \\
n=12,774\end{array}$ & $\begin{array}{c}\text { Total } \\
\mathrm{n}=\mathbf{2 4 , 8 4 4}\end{array}$ \\
\hline Age (years) & $36.8(0.4)$ & $38.3(0.4)$ & $37.5(0.3)$ \\
\hline Age $>50$ & $28.0 \%$ & $30.6 \%$ & $29.3 \%$ \\
\hline \multicolumn{4}{|l|}{ Race } \\
\hline White & $69.8 \%$ & $68.8 \%$ & $69.3 \%$ \\
\hline Black & $11.1 \%$ & $12.3 \%$ & $11.7 \%$ \\
\hline Mexican & $9.4 \%$ & $8.30 \%$ & $8.8 \%$ \\
\hline Other & $9.7 \%$ & $10.6 \%$ & $10.1 \%$ \\
\hline \multicolumn{4}{|l|}{ Education } \\
\hline$<9$ th grade & $17.7 \%$ & $15.9 \%$ & $16.8 \%$ \\
\hline 9-11, no GED & $13.4 \%$ & $13.6 \%$ & $13.5 \%$ \\
\hline Graduated HS, GED & $22.6 \%$ & $21.8 \%$ & $22.2 \%$ \\
\hline Some college, AA & $24.80 \%$ & $27.9 \%$ & $26.4 \%$ \\
\hline College or above & $21.5 \%$ & $20.8 \%$ & $21.1 \%$ \\
\hline \multicolumn{4}{|l|}{ BMI (kg/m2) } \\
\hline BMI & $26.6(0.1)$ & $26.7(0.1)$ & $26.7(0.1)$ \\
\hline $\mathrm{BMI}<30$ & $71.2 \%$ & $68.1 \%$ & $69.6 \%$ \\
\hline $\mathrm{BMI}>=30$ & $28.8 \%$ & $31.9 \%$ & $30.4 \%$ \\
\hline \multicolumn{4}{|l|}{$25(\mathrm{OH}) \mathrm{D}$ Level (nmol/L) } \\
\hline$<30$ & $3.5 \%$ & $6.4 \%$ & $5.0 \%$ \\
\hline 30 to $<50$ & $19.9 \%$ & $21.7 \%$ & $20.8 \%$ \\
\hline 50 to $<75$ & $42.7 \%$ & $37.1 \%$ & $39.8 \%$ \\
\hline 75 or above & $33.8 \%$ & $34.8 \%$ & $34.3 \%$ \\
\hline \multicolumn{4}{|l|}{ Blood Pressure (mmHg) } \\
\hline SBP & $121.3(0.3)$ & $119.0(0.3)$ & $120.3(0.3)$ \\
\hline DBP & $70.2(0.2)$ & $68.4(0.2)$ & $69.3(0.2)$ \\
\hline Taking antihypertensives & $15.2 \%$ & $18.1 \%$ & $16.7 \%$ \\
\hline \multicolumn{4}{|l|}{ Misc. } \\
\hline Diabetes & $5.5 \%$ & $5.8 \%$ & $5.7 \%$ \\
\hline GFR (mL/min per $1.73 \mathrm{~m} 2)$ & $97.5(0.4)$ & $98.0(0.5)$ & $97.5(0.4)$ \\
\hline Caloric intake (kcal) & $2509.3(14.6)$ & $1815.9(7.9)$ & $2153.8(10.0)$ \\
\hline Calcium intake (mg) & $1026.5(11.5)$ & $806.6(8.4)$ & $913.8(9.0)$ \\
\hline Alcohol use (\# of drinks per day) & $0.8(0.03)$ & $0.24(0.1)$ & $0.5(.02)$ \\
\hline
\end{tabular}




\section{Appendix D.2: Table II: Mean Differences in 25(OH)D}

Table II: Mean Differences in Measures of 25(0H)D Among Study Population in NHANES (2001-2006)

\begin{tabular}{lccccc}
\hline & $\mathbf{3 0}$ (nmol/L) & $\mathbf{3 0 - 4 9 . 9}(\mathbf{n m o l} / \mathbf{L})$ & $\mathbf{5 0 - 7 4 . 9}(\mathbf{n m o l} / \mathbf{L})$ & $\mathbf{> 7 5}(\mathbf{n m o l} / \mathbf{L})$ & $\boldsymbol{P}$ \\
\hline Age (years) & $41.7(0.6)$ & $41.6(0.4)$ & $39.7(0.4)$ & $32.0(0.5)$ & $<0.001$ \\
BMI (kg/m2) & $30.9(0.4)$ & $28.9(0.2)$ & $26.8(0.2)$ & $24.3(0.2)$ & $<0.001$ \\
SBP (mmHg) & $123.9(0.7)$ & $122.7(0.3)$ & $120.0(0.3)$ & $118.2(0.5)$ & $<0.001$ \\
DBP (mmHg) & $70.7(0.5)$ & $70.5(0.3)$ & $69.4(0.3)$ & $68.1(0.3)$ & $<0.001$ \\
GFR (mL/min per 1.73m2) & $104.0(1.1)$ & $100.3(0.6)$ & $97.2(0.5)$ & $94.9(0.5)$ & $<0.001$ \\
Caloric intake (kcal) & $1994.1(29.5)$ & $2124.5(16.9)$ & $2226.1(16.7)$ & $2108.2(18.1)$ & $<0.001$ \\
Calcium intake (mg) & $642.9(13.8)$ & $799.1(9.3)$ & $948.8(10.8)$ & $984.4(12.9)$ & $<0.001$ \\
Alcohol use (\# drinks per day) & $0.4(0.1)$ & $0.4(0.02)$ & $0.5(0.02)$ & $0.5(0.03)$ & $<0.001$ \\
Taking antihypertensives & $22.50 \%$ & $21.50 \%$ & $17.70 \%$ & $11.70 \%$ & $<0.001$ \\
Diabetes & $10.3 \%$ & $8.4 \%$ & $5.6 \%$ & $3.3 \%$ & $<0.001$ \\
Male & $37.45 \%$ & $47.44 \%$ & $52.27 \%$ & $47.92 \%$ & $<0.001$ \\
Race & & & & & \\
White & $30.9 \%$ & $50.5 \%$ & $74.5 \%$ & $80.2 \%$ & $<0.001$ \\
Black & $49.0 \%$ & $22.4 \%$ & $6.5 \%$ & $5.8 \%$ & $<0.001$ \\
Mexican & $10.3 \%$ & $12.4 \%$ & $9.2 \%$ & $6.1 \%$ & $<0.001$ \\
Other & $9.8 \%$ & $14.7 \%$ & $9.8 \%$ & $7.9 \%$ & $<0.001$ \\
Education & & & & & \\
$<9$ th grade & $9.9 \%$ & $15.1 \%$ & $16.7 \%$ & $19.3 \%$ & $<0.001$ \\
9-11, no GED & $21.7 \%$ & $15.4 \%$ & $12.4 \%$ & $12.2 \%$ & $<0.001$ \\
Graduated HS, GED & $26.1 \% \%$ & $22.6 \%$ & $21.3 \%$ & $22.2 \%$ & $<0.001$ \\
Some college, AA & $28.7 \%$ & $28.4 \%$ & $26.0 \%$ & $25.1 \%$ & $<0.001$ \\
College or above & $13.4 \%$ & $18.5 \%$ & $23.5 \%$ & $21.1 \%$ & $<0.001$ \\
& & & & &
\end{tabular}




\section{Appendix D.3: Table III: Linear Regression Models}

Table III: Multivariable Adjusted Differences in Blood Pressure by 25(OH)D Groups Among Study Population in NHANES (2001-2006)

\begin{tabular}{|l|c|c|c|}
\hline \multicolumn{3}{|c|}{ Model I: Adjusts for age, gender, race \& education } \\
\hline All Participants & Systolic Blood Pressure & $\boldsymbol{P}$ & \multicolumn{2}{c|}{ Diastolic Blood Pressure } \\
\hline$<30(\mathrm{nmol} / \mathrm{L})$ & Referent & & Referent \\
\hline $30-49.9(\mathrm{nmol} / \mathrm{L})$ & $-0.76(-2.03,0.51)$ & 0.24 & $-0.11(-1.02,0.80)$ \\
\hline $50-74.9(\mathrm{nmol} / \mathrm{L})$ & $-2.41(-3.84,-0.98)$ & 0.001 & $-1.11(-206,-1.15)$ \\
\hline$>75(\mathrm{nmol} / \mathrm{L})$ & $-2.78(-4.24,-1.33)$ & $<0.001$ & $-1.86(-2.83,-0.88)$ \\
\hline P Trend & & $<0.001$ & 0.02 \\
\hline
\end{tabular}

Model II: Adjusts for age, gender, race, education, GFR, antihypertensives, caloric intake \& calcium intake

\begin{tabular}{|l|c|c|c|}
\hline All Participants & Systolic Blood Pressure & $\boldsymbol{P}$ & Diastolic Blood Pressure \\
\hline$<30(\mathrm{nmol} / \mathrm{L})$ & Referent & & Referent \\
\hline $30-49.9(\mathrm{nmol} / \mathrm{L})$ & $-0.36(-1.89,0.33)$ & 0.57 & $-0.28(-1.17,0.60)$ \\
\hline $50-74.9(\mathrm{nmol} / \mathrm{L})$ & $-1.71(-3.17,-0.24)$ & 0.024 & $-0.44(-1.57,0.69)$ \\
\hline$>75(\mathrm{nmol} / \mathrm{L})$ & $-1.86(-3.43,-0.29)$ & 0.021 & $-0.91(-2.22,0.39)$ \\
\hline P Trend & & $<0.001$ & 0.43 \\
\hline & & & 0.16 \\
\hline
\end{tabular}

Model III: Adjusts for age, gender, race, education, GFR, antihypertensives, caloric intake, calcium intake, diabetes \& alcohol use

\begin{tabular}{|l|c|c|c|}
\hline All Participants & Systolic Blood Pressure & $\boldsymbol{P}$ & Diastolic Blood Pressure \\
\hline$<30(\mathrm{nmol} / \mathrm{L})$ & Referent & & Referent \\
\hline $30-49.9(\mathrm{nmol} / \mathrm{L})$ & $-0.01(-1.42,1.40)$ & 0.987 & $0.22(-0.84,1.28)$ \\
\hline $50-74.9(\mathrm{nmol} / \mathrm{L})$ & $-1.54(-3.08,-0.01)$ & 0.048 & $-0.28(-1.47,0.91)$ \\
\hline$>75(\mathrm{nmol} / \mathrm{L})$ & $-1.69(-3.41,0.03)$ & 0.054 & $-0.75(-2.17,0.67)$ \\
\hline P Trend & & $<0.001$ & 0.53 \\
\hline
\end{tabular}




\section{Appendix D.4: Scatter Plot Diagrams}
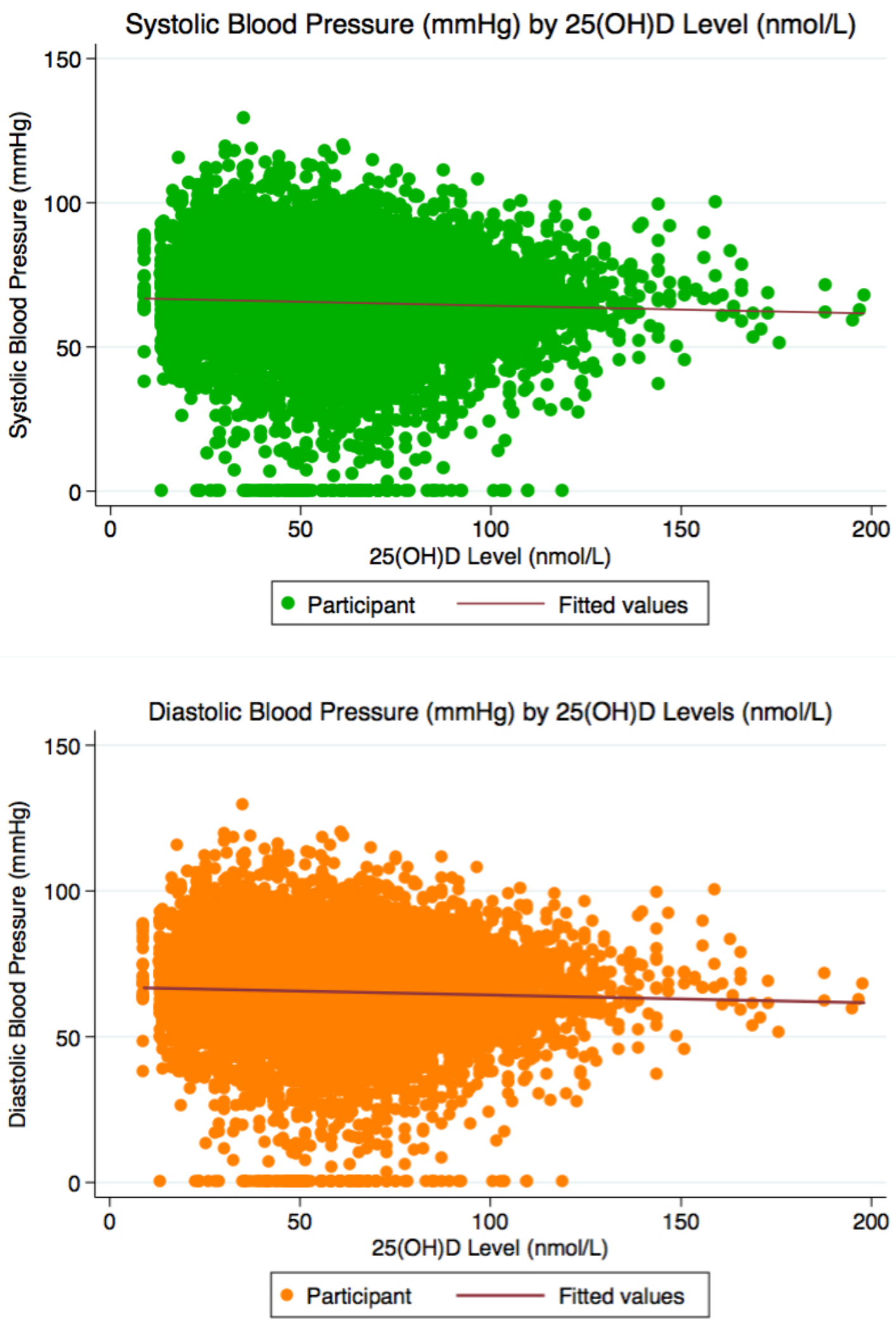
VITAMIN D, CALCIUM AND BLOOD PRESSURE IN U.S.

Appendix D.5: Box Plot Diagram

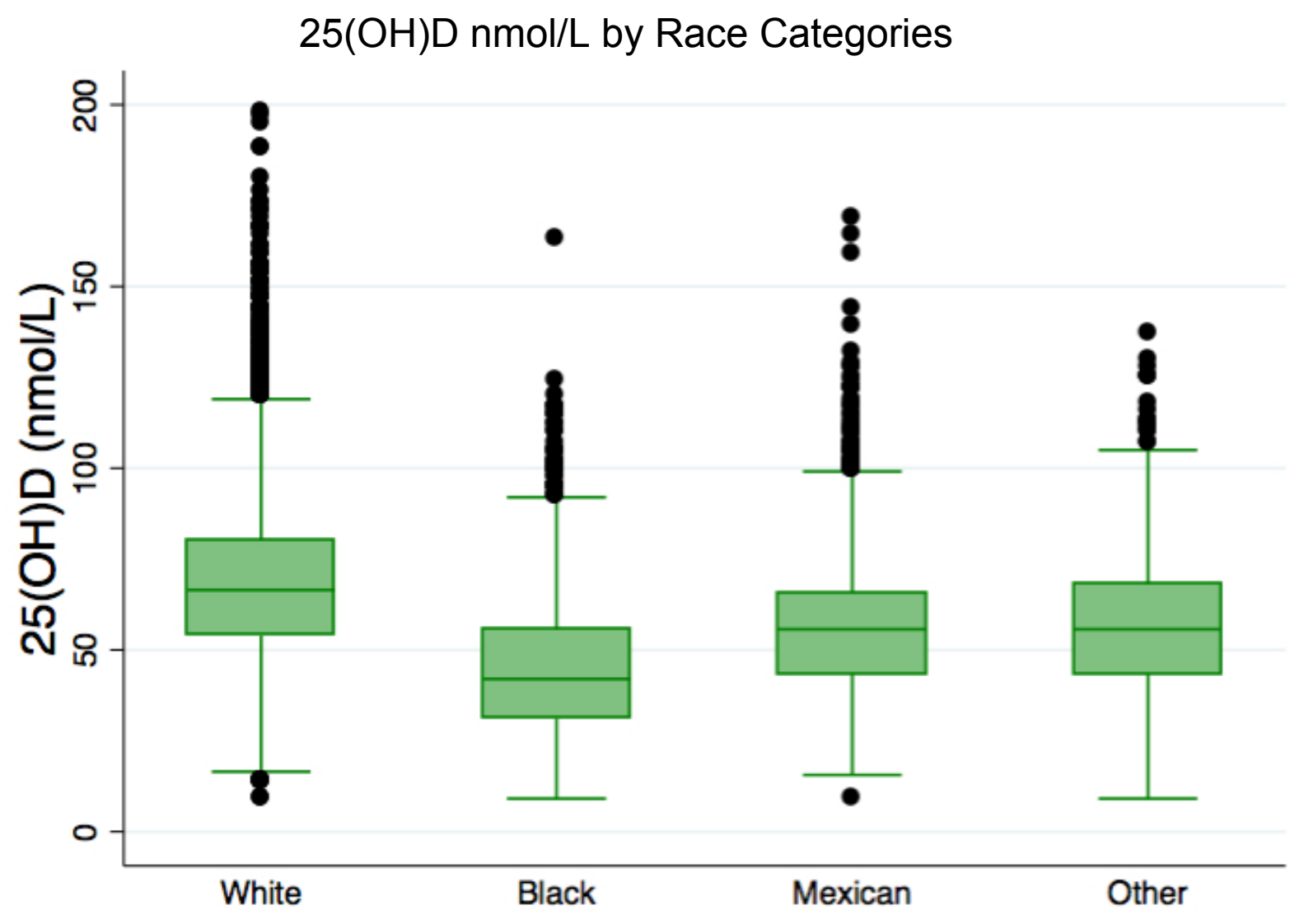


Appendix D.6: Spline Plot Graphs
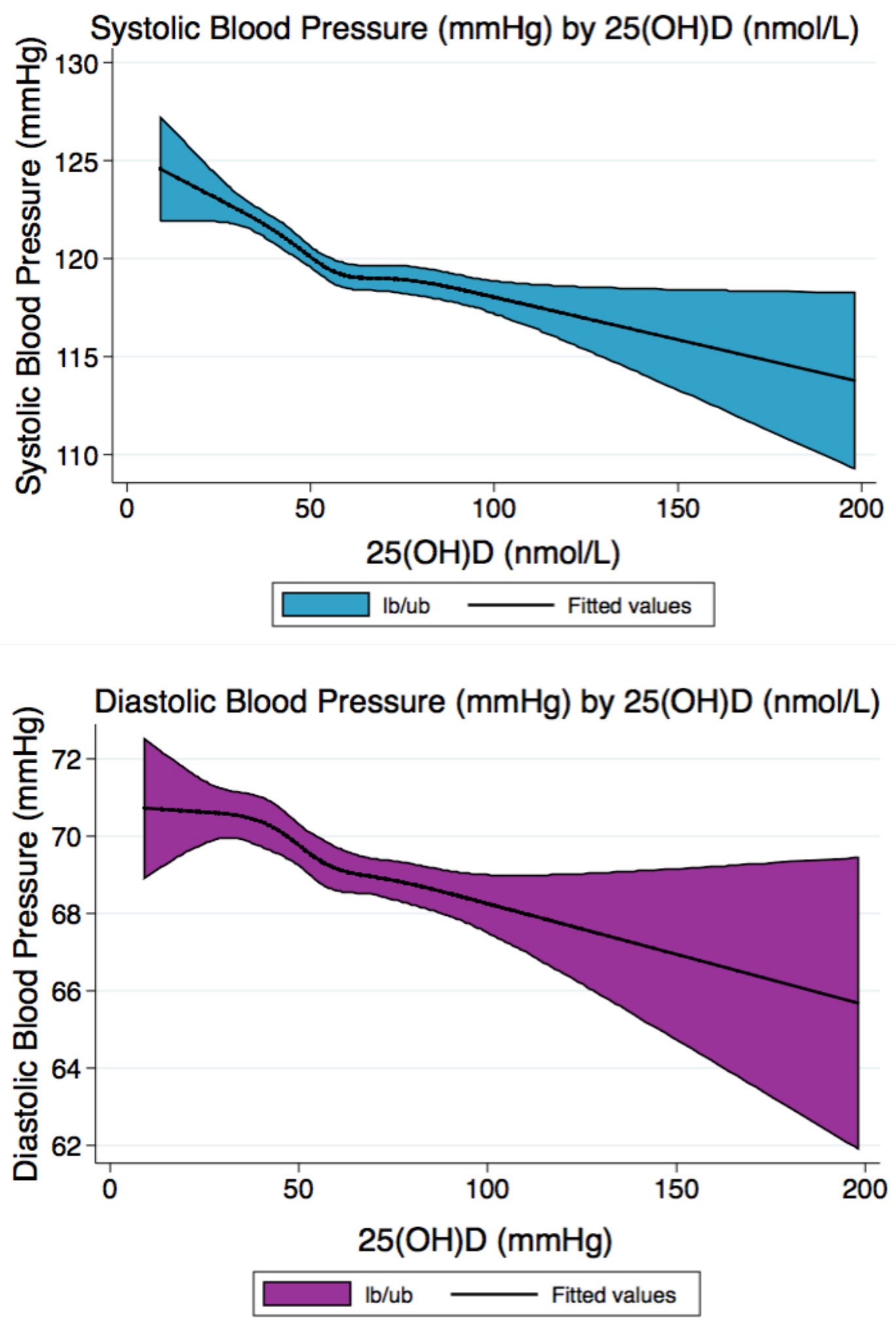
VITAMIN D, CALCIUM AND BLOOD PRESSURE IN U.S.

Appendix D.7: Contour Plot of 25(OH)D by Log of Calcium
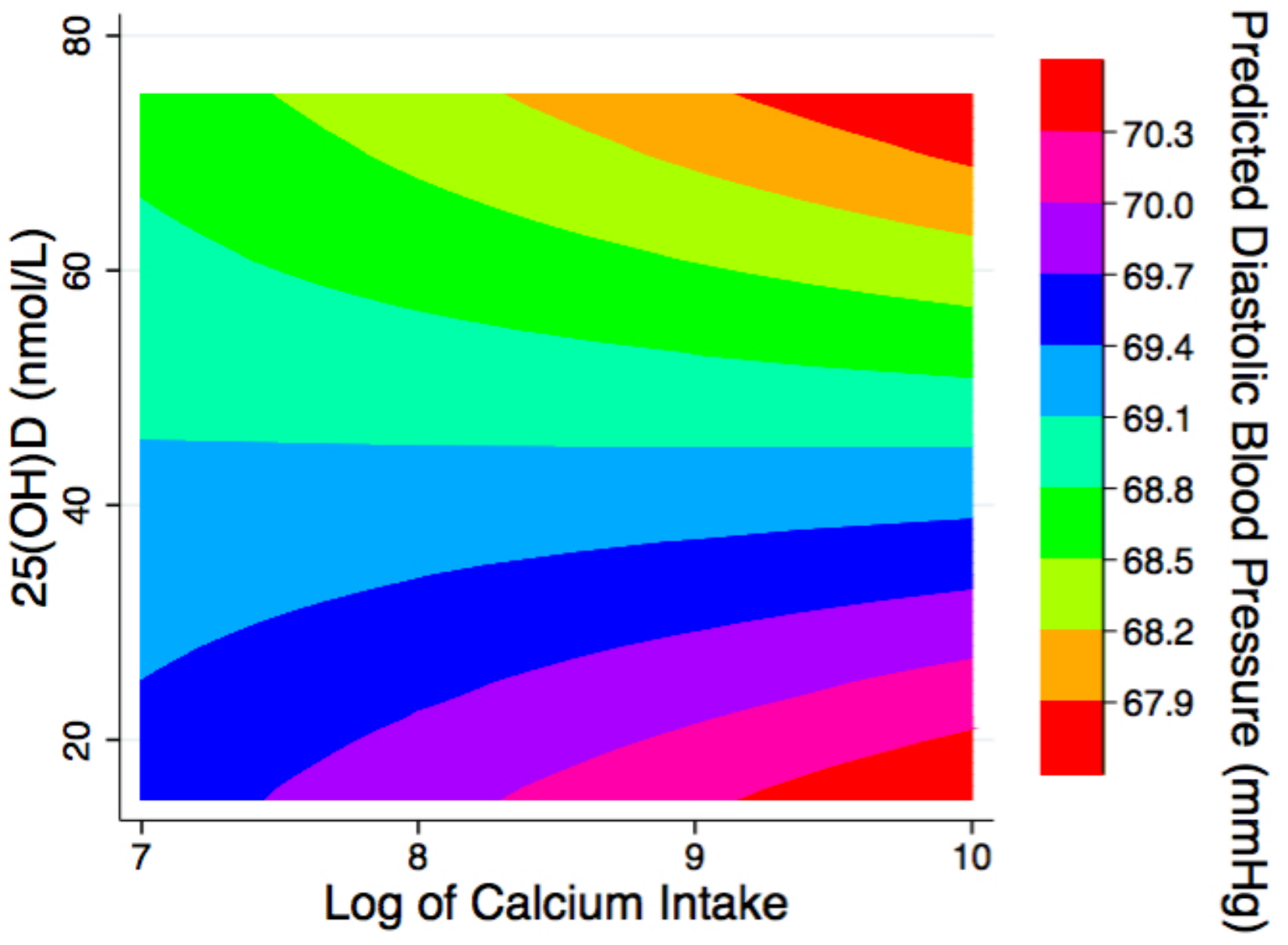